\title{
Community Attitudes Toward Near-Death Experiences: An Australian Study
}

\author{
Allan Kellehear, Ph.D. \\ Deakin University \\ Patrick Heaven, Ph.D. \\ Riverina-Murray Institute
}

ABSTRACT: In an Australian survey of community attitudes toward neardeath experiences (NDEs), 173 respondents were asked to read a hypothetical description of an NDE and to select from a range of explanations that might approximate their own. Fifty-seven percent of the respondents believed the NDE was evidence of life after death, while less than 2 percent believed the NDE was a sign of mental illness. Women, younger persons, and those who professed a belief in life after death were more likely to react positively to the NDE described.

Many people who report a near-death experience (NDE) express a reluctance to disclose their experiences to others for fear of ridicule, negative labelling, stigma, or rejection. Is there a widespread social basis for this fear?

Some surveys of social attitudes toward the NDE have been conducted with limited and special samples. For example, David Royse (1985) conducted a survey of 174 religious clergy, an "almost exclusively male sample." He found attitudes to be positive and generally supportive of the NDEr. On the other hand, Annalee Oakes (1984)

Dr. Kellehear is Lecturer in Sociology at Deakin University, and Dr. Heaven is with the School of Humanities and Social Sciences at the Riverina-Murray Institute in New South Wales. Requests for reprints should be addressed to Dr. Kellehear at the School of Social Sciences, Deakin University, Victoria, Australia 3217. 
found a generally negative set of attitudes among her sample of 30 critical care nurses. George Gallup, Jr. (1982) conducted a broad community survey of attitudes toward the afterlife and polled people on "verge-of-death" experiences. That survey, however, did not solicit their explanations of these experiences, nor did Gallup ask respondents their attitude toward those who claimed to have had such experiences. Surveys examining these issues and using community samples do not exist in the current literature. Yet the assumption of negative community attitudes is a recurrent item in the popular and academic writing on the NDE, and is a view widely supported by anecdotal evidence.

In 1975, Raymond Moody, Jr. devoted a section in his book Life After Life to the topic of "telling others." The section describes rejecting social experiences directed at those who attempted to tell others about their NDE. According to Moody (1975, p. 86), "Others tried at first to tell someone else, but were rebuffed, so they resolved from then on to remain silent." One of Moody's respondents spoke of it in this way: "You learn very quickly that people don't take to this as easily as you would like them to" (Moody 1975, p. 87).

Michael Sabom (1982) began his book with a personal account of his own initial skepticism but also later documented those of others (1982, p. 36). Kimberly Clark (1984) also observed that many of her clients feared telling others, especially their doctors, for fear that they would think them "crazy." Charles Flynn (1986, pp. 16-17) reported that near-death experiencers (NDErs) frequently encountered denials or negative labelling of their experiences. People around NDErs sometimes implied or suggested that a psychiatric problem might be developing for the NDEr. Others asked the NDEr not to raise the subject again. Recently Bruce Greyson and Barbara Harris (1987, p. 42) listed some of the interpersonal problems created when NDErs recounted their experiences to others. These included rejection, ridicule, being ostracized from family and friends, or being regarded as psychotic or hysterical.

Individual accounts of social reactions have described a variety of attitudes in the community but these have not indicated the proportion of the population in these attitude categories. Furthermore such accounts tell us little about the social influences that help shape these attitudes. Therefore, the purpose of the present study was to investigate community explanations about the NDE and to describe the nature and proportional range of attitudes to a hypothetical NDE. We also decided to investigate the relationship between these attitudes and selected socio-demographic variables such as age, sex and education level. 


\section{Method}

\section{Sample}

Undergraduate college students were asked to distribute the questionnaires to anyone they chose to approach, with the constraint that these were not to be other students, that the respondents should be older than eighteen, and that they should strive to sample as widely as possible in terms of socioeconomic status and age. The resulting sample is not representative of the general Australian population, but it was hoped that it would be diverse enough to make generalizations possible.

Responses were received from 173 respondents $(77$ males and $96 \mathrm{fe}$ males). Forty-nine respondents were aged between 18 and 25 years, 65 respondents were between 26 and 40 years, 43 respondents were between 41 and 60 years, and 13 were older than 61 years of age. Eight respondents had completed primary school only, 32 had some secondary education, 41 had completed high school, 41 had post-secondary technical training, 27 had some college or university education, while 23 had completed a degree or diploma.

\section{Questionnaire}

Short, one-line explanations of the NDE were compiled using the literature as a guide. The main explanations were used with the exception of "depersonalization," which was considered to be a relatively esoteric explanation, aside from the obvious difficulty of translating the concept into accurate and readily understood parlance. The final list appears in Table 1.

A further list of statements, representing a range of possible attitudes to a person recalling an NDE, was also compiled. These included positive statements (e.g., I would encourage discussion of his/her feelings whatever these might be), negative statements (e.g., I would visit this person less often), and neutral statements (e.g., My reaction would depend on this person's reaction to the experience). The final list of these appears in Table 2.

The beginning of each questionnaire contained a vignette of a typical NDE that described five main elements: tunnel sensation, out-of-body experience, meeting deceased relatives, meeting a bright light, and experiencing a life review. Questionnaires were divided into two types. Either the vignette portrayed a "close friend or family member" or "an acquaintance." The wording of the instructions was based on the narrative models of intimate/nonintimate relations developed by Margaret Fieweger and Michael Smilowitz (1984-85). The questionnaire was tested on a small group $(n=20)$ of undergraduate students who were asked to comment on the clarity of the statements as well as their impression of whether these attitudes appeared to them as positive, negative, or neutral. 


\section{Procedure}

The study was conducted in October, 1987. Each respondent was approached by a student and asked to complete a questionnaire anonymously in the privacy of his or her home. Eighty-eight respondents received a questionnaire referring to "an acquaintance," while 85 per. cent received a questionnaire referring to a close friend or family mem. ber.

\section{Results}

Respondents were asked to select the explanation that best explained the vignette for them. The percentage of all respondents ("acquaintance" and "close friend/relative") selecting each explanation is shown in Table 1.

It is noteworthy that $57.80 \%$ of the respondents interpreted the vignette as possible evidence of life after death. Only $1.73 \%$ saw it as the beginning of mental illness, while $17.91 \%$ did not know how to explain it.

Respondents were also asked to circle four statements that might best describe their reaction to a person recounting the experience to them. The statements are shown in Table 2. Negative statements were scored 0 , neutral statements 1 , and positive statements 2 . The mean score of the "acquaintance" group was $6.1(\mathrm{SD}=1.51)$, while that for the "close friend or relative" group was $6.2(\mathrm{SD}=1.82)(\mathrm{t}=0.39, \mathrm{df}=$ 171 , n.s.). As there was no significant difference in attitude toward the NDE, both groups were combined for further analysis.

A 2 (sex) $\times 4$ (age) $\times 6$ (education) analysis of variance for the total group was computed on each individual's total score as calculated for

Table 1

\section{Responses to Seven Explanations for the NDE}

\begin{tabular}{lrr}
\hline Explanations & $N$ & $\%$ \\
\hline 1. It was a passing hallucination. & 15 & 8.67 \\
2. It was a dream. & 11 & 6.34 \\
3. It was the beginning of a mental illness. & 3 & 1.73 \\
4. It was the side effects of medical drugs/techniques. & 7 & 4.04 \\
5. It was possible evidence of life after death. & 100 & 57.80 \\
6. It was the product of a vivid imagination. & 6 & 3.46 \\
7. I don't know how to explain it. & 31 & 17.91 \\
\hline
\end{tabular}




\section{Table 2}

\section{Possible Reactions to Vignette}

1. I would try to change the subject. -

2. I would seek professional advice before deciding how to respond. 0

3. I would be openly fascinated and interested. +

4. I would humour this person until the delusion had passed. -

5. My reaction would depend on this person's reaction to the experience. 0 .

6. I would reassure them that this did not lessen my regard for them. +

7. I would be suspicious of this person's motives. -

8. I would explore with them the variety of possible explanations for this experience. +

9. I would visit this person less often. -

10. I would take a "wait and see" attitude. 0

11. I would be puzzled by the story and tell them so. 0

12. I would encourage discussion of his/her feelings whatever these might be. +

Positive reactions are denoted by $(+)$, negative reactions denoted by $(-)$, neutral reactions denoted by $(0)$.

the statements in Table 2. A significant main effect for sex was obtained $(\mathrm{F}=9.70, \mathrm{df}=1.161, \mathrm{p}<.01)$. A post-hoc analysis revealed women to have more tolerant attitudes than men. No other significant main effects or interactions were observed.

Finally, it was decided to investigate the linear correlations between scores obtained in Table 2 and the demographic variables. These correlations are presented in Table 3.

The correlations indicate that positive reaction to the NDE vignette significantly correlated with sex $(r=.21, p<.01)$, age $(r=-.20$, $p<.01)$ and a belief in a life after death $(r=.30, p<.001)$. That is, females, younger individuals, and those who profess a belief in life after death were more likely to react positively towards the NDE described.

\section{Discussion}

The most surprising and interesting finding of this study is the positive nature of responses to NDEs. Over half the respondents felt 
Table 3

Linear Correlations between Positive Reactions and Demographic Variable

\begin{tabular}{lc}
\hline Variable & $r$ \\
\hline Sex & $.21^{*}$ \\
Age & $-.20^{*}$ \\
Marital Status & .13 \\
Religion & -.12 \\
Education & -.16 \\
Belief in life after death & $.30^{* *}$ \\
\hline
\end{tabular}

${ }^{*} \mathrm{p}<.01 \quad{ }^{* *} \mathrm{p}<.001$

that NDEs represented some form of life after death. This is positive in the specific sense of locating the explanation within the legitimate world of possible experiences rather than attempting to explain the experiences as a defect within the individual. Most people are ill equipped to judge others with medical or psychiatric criteria. It is equally true that they are unable to judge if life after death is a distinct possibility. But a judgment leaning towards life after death rather than psychiatric defects within the individual upholds the status of normality for the NDEr. It tends, therefore, not to judge the individual negatively on the basis of an occurrence of an NDE but rather takes the judgment process to a different level, that of the meaning of the content of the experience. For the NDEr, this provides the social opportunity to explore its meaning, whatever the NDEr and his or her intimates eventually conclude, without any accompanying sense of stigma.

It is also noteworthy that only about a quarter of the sample (24.2\%) chose other explanations. In this category, less than $2 \%$ felt that NDErs might be "going crazy," based on their reading of the vignette. The general positiveness of respondent views about the NDE is also reflected in the mean scores for statements described in Table 2. Overall, then, how is one to explain this positive general trend? Several explanations are possible here.

First, it must be remembered that explanations that seek to locate a problem with the NDEr are still significant, despite most of the sample choosing an explanation probably more acceptable to the NDEr. One in four respondents maintained a belief that the NDEr might be hallucinating, dreaming, imagining things, or experiencing side effects of drugs. If this proportion is any indication of a similar proportion in the community as a whole, then what the NDEr might view as negative explanations could still be commonly encountered.

Secondly, because this is a community sample, it is no indication of 
how health professionals might react. This is important, for as Oakes's (1984) study indicated these reactions could be quite negative. This would be consistent with the traditionally negative reactions by medical and nursing staff to any subjects touching on issues of death and dying (Dumont \& Foss, 1972; Noyes \& Clancy, 1977; Devins, 1978-1979; Beilin, 1981-82). Professional reaction might be critical, as those persons are frequently among the first people to whom NDErs attempt to describe their experiences.

More generally, however, initial contacts with anyone who quickly dismisses or rationalizes away the experiences of the NDEr may be enough to deter the NDEr from telling others who might have been more positive and supportive. Early negative reactions, especially if these come from professionals or close friends or relatives, may discourage the NDEr from attempting to explore possible explanations from others in the community.

Finally, most people in this study were familiar with the NDE from newspapers, books or magazines $(79 \%)$ or television, radio or movies $(72 \%)$. Indeed, $10 \%$ of the sample claimed to have had a personal experience similar "to the one described by this survey." The high number of people in this study familiar with the NDE, and possibly the various explanations and debates, may also partly explain the high level of openness to the possibility that the experience is not due to mental illness or to one's imagination. The willingness shown by the sample to choose less stigmatizing medical explanations may be due in part to belief in "life after death" by the majority of the sample (69\%). Early accounts of rejection and negative labelling may partly be a function of widespread ignorance of the experience by the general community.

Perhaps less surprising from this study is the fact that women, those who profess a belief in life after death, and younger people tend to be more positive than others. Women were more likely to explain the NDE as evidence of life after death, and this conforms to the findings of Gallup (1982) and Michael Thalbourne and Erlendur Haraldsson (1984). They observed that a belief in the afterlife is somewhat more common in women. Thalbourne (in press) argues that, in general, gender probably accounts for only about $6 \%$ of the variance in surveys of afterlife belief. Many studies fail to detect a difference at all. In any case, women may be more positive because they are more likely to share many NDEr convictions that the NDE is evidence of life after death. Indeed, this includes many of those who believe in life after death irrespective of gender. All of these people may therefore be more receptive to experiences that lend support to their general belief in the afterlife. 
Perhaps the fact that the young are more tolerant of the NDE is related to general conservative beliefs. Many studies of social attitudes (see for example Wilson, 1973) have shown the elderly to be more conservative than younger individuals. Young people do seem to have more tolerant views about issues that older people may view more cynically or conservatively. For example, in Gallup's (1982) survey, greater numbers of younger people professed a belief in reincarnation, life on other planets, and the possibility of contact with the dead. It would be interesting to conduct a longitudinal study to determine the changes in such tolerant attitudes as individuals grow older.

\section{References}

Beilin, R. (1981-1982). Social functions of the denial of death. Omega, 12, 25-35.

Clark, K. (1984). Clinical interventions with near-death experiencers. In B. Greyson \& C. P. Flynn (Eds.), The near-death experience: Problems, prospects and perspectives. Springfield, IL: Charles C. Thomas, pp. 242-255.

Devins, G. M. (1978-1979). Some subjective reactions of a behavioral scientist involved in thanatological research. International Journal of Psychiatry in Medicine, 9, 307-315.

Dumont, R. G. \& Foss, D. C. (1972). The American way of death: Acceptance or denial. Cambridge, MA: Schenkman.

Fieweger, M. \& Smilowitz, M. (1984-85). Relational conclusion through interaction with the dying. Omega, 15, 161-172.

Flynn, C. P. (1986). After the beyond: Human transformation and the near-death experience. Englewood Cliffs, NJ: Prentice Hall.

Gallup, G., Jr. with Proctor, W. (1982). Adventures in immortality. New York: McGrawHill.

Greyson, B. \& Harris, B. (1987). Clinical approaches to near-death experiencer. Journal of Near-Death Studies, 6, 41-52.

Moody, R. A., Jr. (1975). Life after life. Covington, GA: Mockingbird Books.

Noyes, R. \& Clancy, J. (1977). The dying role: Its relevance to improved patient care. Psychiatry, 40, 41-47.

Oakes, A. R. (1984). Near-death events and critical care nursing. In B. Greyson \& C. P. Flynn (Eds.), The near-death experience: Problems, prospects and perspectives. Springfield, IL: Charles C. Thomas, pp. 223-231.

Royse, D. (1985). The near-death experience: A survey of clergy's attitudes and knowledge. Journal of Pastoral Care, 39, 31-42.

Sabom, M. (1982). Recollections of death. New York: Harper \& Row.

Thalbourne, M. A. \& Haraldsson, E. (1984). A retrospective search for correlates of belief in life after death. I. Icelandic data In R. A. White \& R. S. Broughton (Eds.), Research in parapsychology, 1983. Metuchen, NJ: Scarecrow, pp. 62-66.

Thalbourne, M. A. (in press). On the psychology of belief in life after death. In G. K. Zollschan, J. F. Schumaker, \& G. F Walsh (Eds.), Exploring the paranormal: Different perspectives on belief and experience.

Wilson, G. D. (1973). The psychology of conservatism. London: Academic Press. 